AGRICULTURE AND BIOLOGY JOURNAL OF NORTH AMERICA

ISSN Print: 2151-7517, ISSN Online: 2151-7525, doi:10.5251/abjna.2012.3.9.374.384

(C) 2012, ScienceHuß, http://www.scihub.org/ABJNA

\title{
Nutritional values of the lipid composition of the free-range chicken eggs
}

\author{
Emmanuel Ilesanmi Adeyeye
}

\author{
Department of Chemistry, University of Ado Ekiti, PMB 5363, Ado- Ekiti, Nigeria
}

\begin{abstract}
Poultry eggs are eaten in most areas of the world with fewer social taboos associated with them than pigs and cattle. The most commonly used bird eggs are those from chicken. In Nigeria, the domestic foul dominates the poultry industry. Of the 120 million indigenous poultry population in Nigeria, the domestic fowl constitutes about $91 \%$ of this. For this reason, the present work tried to evaluate the nutritional levels of the lipid composition of the free-range fertilized cooked chicken eggs. Five eggs were involved in the study and they were collected at once. The following experimental procedures were carried out on the yolk and the albumen using standard analytical methods: crude fat determination, preparation of methyl esters and fatty acid analysis. Also determined was the quality assurance of the determinations to ensure their accuracies, calculation of uncertainty interval percentage (UIP) particularly for the fatty acid values. Statistical evaluations carried out included: linear correlation coefficient $\left(r_{\mathrm{xy}}\right)$, coefficient of determination $\left(r_{x y}{ }^{2}\right)$, linear regression coefficient $\left(R_{x y}\right)$, coefficient of alienation $\left(C_{A}\right)$ and index of forecasting efficiency (IFE). The study reports the nutritional values of the lipid composition of the free-range chicken eggs analyzing separately the yolk and the albumen. The yolk was $32.8 \%$ of the total egg weight while the albumen was $53.8 \%$. The total crude fat in yolk was $22.9 \mathrm{~g} / 100 \mathrm{~g}$ whilst it was $0.001 \mathrm{~g} / 100 \mathrm{~g}$ in albumen. The total fatty acid in yolk was $19.0 \mathrm{~g} / 100 \mathrm{~g}$; it was $0.00083 \mathrm{~g} / 100$ $\mathrm{g}$ in albumen. The SFA level was $35.0 \%$ in total fatty acids in yolk; it was $31.8 \%$ in albumen. Total monounsaturated fatty acids (MUFA) in yolk was $43.5 \%$ but $42.9 \%$ in albumen. Total $n-6$ PUFA was $21.8 \%$ in yolk and $25.2 \%$ in albumen. The PUFA/SFA was 0.62 in yolk and 0.79 in albumen. Lecithin was high in yolk [115 mg/100 g; $46.0 \%$ but at trace level [23.3e-3 mg/100 g; $63.1 \%]$ in albumen. Sterol was not detected in the albumen but total sterol in the yolk was 386 $\mathrm{mg} / 100 \mathrm{~g}$ having cholesterol level of $86.3 \mathrm{mg} / 100 \mathrm{~g} \mathrm{(22.4 \% ).} \mathrm{The} \mathrm{levels} \mathrm{of} \mathrm{MUFA} \mathrm{+} \mathrm{PUFA} \mathrm{in} \mathrm{yolk}$ was $65.3 \%$ and $68.1 \%$ in albumen showing that the chicken egg could be classified as being made up majorly of unsaturated oil. Free-range laying hens are given outdoor access instead of being contained in crowded cages; this gives them wide range of various feeding opportunities. This report showed the free-range chicken eggs yolk to be far more concentrated in crude fat; total fatty acids; SFA; MUFA; n-6 PUFA; high PUFA/SFA; high lecithin; high cephalin; high stigmasterol and cholesterol than the corresponding albumen. The cholesterol level was also below the average recommended level.
\end{abstract}

Keywords: Free-range chicken, eggs, lipid composition.

\section{INTRODUCTION}

Bird eggs are a common food and one of the most versatile ingredients used in cooking. They are important in many branches of the modern food industry (Montagne, 2001). The most commonly used bird eggs are those from chicken. Duck and goose eggs, and smaller eggs such as quail eggs are occasionally used as a gourmet ingredient, as are the largest bird eggs, from ostriches. Gull eggs are considered a delicacy in England (Roux and Brigdale, 2006), as well as in some Scandinavian countries, particularly in Norway. In some African countries, guinea fowl eggs are commonly seen in market places, especially in the spring of each year (Stadelman, 1995). Pheasant eggs and emu eggs are perfectly edible but less widely available (Roux and Brigdale, 2006).

In Nigeria, more emphasis is laid on domestic fowl to the neglect of other classes of poultry. As a result domestic fowl dominated the poultry industry. Of the 150 million poultry population, 120 million (80\%) were indigenous. Domestic fowl constituted $91 \%$ of this while guinea fowl, duck, turkey and others were 4 $\%, 3 \%$ and $2 \%$ respectively (Adenowo et al., 1999).

Work had been carried out on the species variations in chemical composition of local poultry eggs in Nigeria; this included the chicken eggs (Adenowo et al., 1999). In the present report, attempt was made to evaluate the nutritional levels of the lipid composition 
of the free-range fertilized cooked chicken eggs. The samples used were the yolk and albumen of the eggs while the lipids evaluated for were fatty acids, phospholipids and the sterols.

\section{MATERIALS AND METHODS}

Collection and treatment of samples: The chicken eggs were purchased from local poultry keepers from Ado-Ekiti, Nigeria. Five eggs were involved in the study and they were collected at once. The eggs were cooked, cooled, weighed whole, cracked to remove yolk and the albumen and weighed, and finally the shell was weighed. Both the yolk and albumen were separately oven-dried and ground to powder, sieved using $200 \mathrm{~mm}$ mesh and kept in freezer in McCartney bottles pending analysis.

Crude fat determination: Crude fat was determined according to AOAC (2005) method. The crude fat The gas chromatography conditions for the analysis of fatty acid methyl esters were as follows:

GC:

HP 5890 powered with HP

ChemStation rev. A09.01

[1206] software (GMI, Inc, Minnesota, USA)

Injection type:

Split ratio:

Carrier gas:

Inlet temperature:

Column type:

Column dimensions:

Oven programme:

Detector:

Detector temperature:

Hydrogen pressure:

Compressed air:

Split injection

20:1

Nitrogen

$250{ }^{\circ} \mathrm{C}$

HP-INNOWax

$30 \mathrm{~m} \times 0.25 \mathrm{~mm} \times 0.25 \mu \mathrm{m}$

Initial temperature at $60^{\circ} \mathrm{C}$

First ramping at $10^{\circ} \mathrm{C} / \mathrm{min}$ for $20 \mathrm{~min}$,

maintained for 4 min

Second ramping at $15{ }^{0} \mathrm{C} / \mathrm{min}$ for $4 \mathrm{~min}$,

maintained for $10 \mathrm{~min}$

Flame ionization detector (FID)

$320^{\circ} \mathrm{C}$

$22 \mathrm{psi}$

$35 \mathrm{psi}$

The peaks were identified by comparison with standard fatty acid methyl esters.

Sterol analysis: The sterol analysis was as described by AOAC (2005). The aliquots of the extracted fat were added to the screw-capped test tubes. The sample was saponified at $95{ }^{\circ} \mathrm{C}$ for 30 min, using $3 \mathrm{ml}$ of $10 \% \mathrm{KOH}$ in ethanol, to which $0.20 \mathrm{ml}$ of benzene had been added to ensure miscibility. Deionised water $(3 \mathrm{ml})$ was added and 2 $\mathrm{ml}$ of hexane was used in extracting the nonof sterols were as follows: values were used to calculate the theoretical total fatty acids by multiplying with a conversion factor of 0.83 (for egg) (Greenfield and Southgate, 2003).

Preparation of methyl esters and analysis: $50 \mathrm{mg}$ of the extracted fat content of the sample was saponified for $5 \mathrm{~min}$ at $95{ }^{\circ} \mathrm{C}$ with $3.4 \mathrm{ml}$ of $0.5 \mathrm{M}$ $\mathrm{KOH}$ in dry methanol. The mixture was neutralized by $0.7 \mathrm{M} \mathrm{HCl} .3 \mathrm{ml}$ of $14 \%$ boron triflouride in methanol was added (AOAC 2005). The mixture was heated for $5 \mathrm{~min}$ at the temperature of $90{ }^{\circ} \mathrm{C}$ to achieve complete methylation process. The fatty acid methyl esters were thrice extracted from the mixture with redistilled $\mathrm{n}$-hexane. The content was concentrated to $1 \mathrm{ml}$ for gas chromatographic analysis and $1 \mu \mathrm{l}$ was injected into the injection pot of the GC.
GC:
HP 5890 powered with HP ChemStation rev. A09.01
Injection type: [1206] software (GMI, Inc, Minnesota, USA)
Split ratio:

$\begin{array}{ll}\text { GC: } & \text { HP } 5890 \text { powered with HP } \\ & \text { ChemStation rev. A09.01 } \\ & {[1206] \text { software (GMI, Inc, Minnesota, USA) }} \\ \text { Injection type: } & \text { Split injection } \\ \text { Split ratio: } & 20: 1\end{array}$
saponifiable materials. Three extractions, each with 2 $\mathrm{ml}$ of hexane, were carried out for $1 \mathrm{~h}, 30 \mathrm{~min}$ and 30 min respectively, to achieve complete extraction of the sterols. The hexane was concentrated to $1 \mathrm{ml}$ in the vial for gas chromatographic analysis and $1 \mu \mathrm{l}$ was injected into the injection pot of GC. The peaks were identified by comparison with standard sterols. The gas chromatography conditions for the analysis 
Agric. Biol. J. N. Am., 2012, 3(9): 374-384

$\begin{array}{ll}\text { Carrier gas: } & \text { Nitrogen } \\ \text { Inlet temperature: } & 250^{\circ} \mathrm{C} \\ \text { Column type: } & \text { HP-INNOWax } \\ \text { Column dimensions: } & 30 \mathrm{~m} \times 0.25 \mathrm{~mm} \times 0.25 \mu \mathrm{m} \\ \text { Oven programme: } & \text { Initial temperature at } 60{ }^{\circ} \mathrm{C} \\ & \text { First ramping at } 10^{\circ} \mathrm{C} / \mathrm{min} \text { for } 20 \mathrm{~min}, \\ & \text { maintained for } 4 \mathrm{~min} \\ & \text { Second ramping at } 15{ }^{\circ} \mathrm{C} / \mathrm{min} \text { for } 4 \mathrm{~min}, \\ & \text { maintained for } 10 \mathrm{~min} \\ \text { Detector: } & \text { Flame ionization detector (FID) } \\ \text { Detector temperature: } & 320^{\circ} \mathrm{C} \\ \text { Hydrogen pressure: } & 22 \mathrm{psi} \\ \text { Compressed air: } & 35 \mathrm{psi}\end{array}$

The peaks were identified by comparison with standard fatty acid methyl esters.

Phospholipids analysis: Modified method of Raheja et al. (1973) was employed in the analysis of the extracted oil phospholipids content determination. $0.01 \mathrm{~g}$ of the extracted fat was added to the test tubes. To ensure complete dryness of the oil for phospholipids analysis, the solvent was completely removed by passing stream of nitrogen gas on the oil. $0.40 \mathrm{ml}$ of chloroform was added to the content of the tube and it was followed by the addition of 0.10 $\mathrm{ml}$ of chromogenic solution. The content of the tube was heated at the temperature of $100{ }^{\circ} \mathrm{C}$ in water bath for about $1 \mathrm{~min}$ and $20 \mathrm{sec}$. The content was allowed to cool to the laboratory temperature and 5 $\mathrm{ml}$ of hexane was added and the tube with its content shaken gently several times. The solvent and the aqueous layers were allowed to be separated. The hexane layer was recovered and allowed to be concentrated to $1.0 \mathrm{ml}$ for gas chromatographic analysis using pulse flame photometric detector. The gas chromatography conditions for the analysis of phospholipids were as follows:
HP 5890 powered with HP

ChemStation rev. A09.01

[1206] software (GMI, Inc, Minnesota, USA)

Injection type:

Split ratio: Split injection

20:1

Nitrogen

$250^{\circ} \mathrm{C}$

HP 5

$30 \mathrm{~m} \times 0.25 \mathrm{~mm} \times 0.25 \mu \mathrm{m}$

Initial temperature at $50^{\circ} \mathrm{C}$

First ramping at $10^{\circ} \mathrm{C} / \mathrm{min}$ for $20 \mathrm{~min}$, maintained for 4 min

Second ramping at $15{ }^{\circ} \mathrm{C} / \mathrm{min}$ for $4 \mathrm{~min}$, maintained for $5 \mathrm{~min}$.

Detector:

Detector temperature:

Hydrogen pressure:

$320{ }^{\circ} \mathrm{C}$

$20 \mathrm{psi}$

30 psi

The peaks were identified by comparison with standard phospholipids.

Quality assurance: For the purpose of ensuring the accuracy of the results obtained, the followings were carried out: standard chromatograms were prepared for sterols, phospholipids and fatty acid methyl esters which were then compared with respective analytical results; calibration curves were prepared for all the standard mixtures and correlation coefficient was determined for each fatty acid parameter (28), same for sterol (4) and phospholipids (5). Correlation coefficient should be $>0.95$ for the result to be acceptable. It is a statistical index that shows the quality assurance of the calibration curve obtained. It 
was performed with the Hewlett Packard Chemistry (HPCHEM) software (GMI, Inc 6511 Bunker Lake Blvd Ramsey, Minnesota, 55303 USA). Further on quality assurance, the fatty acid values were subjected to the calculation of uncertainty interval percentage. Certified reference materials (CRMs) play a critical role in validating the accuracy of nutrient data. CRMs are used for several purposes. A range of food CRMs with assigned values and uncertainty intervals (Uls) for many nutrients are currently supplied by several organizations (Phillips et al., 2007). The specified UI for each fatty acid concentration was used to calculate the percentage value to yield the uncertainty interval percentage (UIP), as shown in Eq. 1:

$$
\text { UIP }=(\mathrm{UI} / \text { value }) \times 100 \text {--- Equation } 1
$$

The fatty acids evaluated in certified reference materials (CRMs) were: C12:0, C14:0, C16:0, C18:0, C16:1, C18:1, C18:2, C18:3, C20:0, C20:5, C22:6, C22:0, C22:5 and C24:0 (AOAC, 2005; Phillips et al., 2007). Some CRMs values were available for sterol and phospholipids but none in food samples relevant to this study.

Fatty acids were listed with the chain and double bond numbers. At the data source and reference database levels, values for individual fatty acids are usually expressed as percentages of total fatty acids since this is the most common form of analytical presentation. (It was used here.) At the user database levels, values per $100 \mathrm{~g}$ of food are required. (Value of each fatty acid present in $100 \mathrm{~g}$ of yolk and albumen was calculated.) At all levels of data management both modes of expression are useful for comparative evaluation. A conversion factor derived from the proportion of the total lipid present as fatty acids is required (Paul and Southgate, 1978) for converting percentages of total fatty acids to fatty acids per $100 \mathrm{~g}$ of food. (Crude fat level was multiplied by a conversion factor of 0.83 to convert it to total fatty acids) (Paul and Southgate, 1978). For fatty acids expressed in $\mathrm{g}$ per $100 \mathrm{~g}$ total fatty acids, precision is best limited to the $0.1 \mathrm{~g} / 100 \mathrm{~g}$ level, with trace being set at $<0.06 \mathrm{~g} / 100 \mathrm{~g}$ total fatty acids (Greenfield and Southgate, 2003).

Statistical analysis: Statistical analysis (Oloyo, 2001) was carried out to determine mean, standard deviation, coefficient of variation in percent. Also calculated were linear correlation coefficient $\left(r_{x y}\right)$, coefficient of determination $\left(r_{x y}{ }^{2}\right)$, linear regression coefficient $\left(R_{x y}\right)$ and coefficient of alienation $\left(C_{A}\right)$ and index of forecasting efficiency (IFE). The $r_{x y}$ was subjected to the table (critical) value at $r=0.05$ to see if significant differences existed in the values of fatty acids, sterols and phospholipids between the yolk and albumen of chicken egg.

\section{RESULTS}

The mean weight of the anatomical parts of the egg is shown in Table 1. The weight of the albumen almost doubled the weight of the yolk. In Table 2 the crude fat in the yolk was $22.9 \mathrm{~g} / 100 \mathrm{~g}$ whereas the albumen was almost free of crude fat with a value of $0.001 \mathrm{~g} / 100 \mathrm{~g}$ and this pattern was followed in their calculated total fatty acid values. This wide difference led to high values of coefficient of variation (CV \%).

Table 3 depicts the levels of saturated fatty acid (SFA) and monounsaturated fatty acid (MUFA) of the samples. Both $\mathrm{C} 12: 0$ and $\mathrm{C} 20: 0$ were in traces in both samples (values $<0.06 \%$ total fatty acids) (Greenfield and Southgate, 2003). C16:0 was the most concentrated SFA in both samples whereas C18:1n-6, cis was the most concentrated MUFA in the yolk and C18:1n-9, cis was the most concentrated MUFA in albumen. Total SFA was 35.0 $\%$ (yolk) and $31.8 \%$ (albumen) with respective total MUFA levels of $43.5 \%$ and $42.9 \%$. The CV \% for all the fatty acids (MUFA and SFA) ranged between 0.98-41.6.

Table 4 shows the polyunsaturated fatty acids ( $n-6$ and $n-3$ ) of the samples.

The following fatty acids (FAs) were in traces: C18:3n-6, cis, C20:2n-6, cis, C18:3n-3, C20:5n-3 and C22:6n-3. The most concentrated $n-6$ FA was C18:2n-6, cis in both samples. The total n-6 PUFA was $21.8 \%$ (yolk) and $25.2 \%$ (albumen). The overall levels of MUFA + PUFA was $65.3 \%$ (yolk) and 66.7 $\%$ (albumen) showing both samples to be mostly of unsaturated fatty acids. The CV \% values were generally much lower than the values in Table 3; here it ranged between 0.07-26.7.

The statistical interpretation of the results from Tables 3 and 4 is in Table 5. The $r_{x y}$ was 0.9976 which was significant at $r=0.05$ and the $R_{x y}$ was 0.492 . The coefficient of alienation $\left(\mathrm{C}_{A}\right)$ (non relationship) was low (0.069) but high index of forecasting efficiency (IFE) (0.931) showing a high prediction of relationship in the parameters in the Tables 3 and 4 between yolk and albumen.

The calculated levels of the FAs in $100 \mathrm{~g}$ of yolk and albumen as food are shown in Table 6 . The values 
ranged from 0.047-4.02 $\mathrm{g} / 100 \mathrm{~g}$ in yolk but ranged from 1.58e-6-7.36e-4 g/100 $\mathrm{g}$ in the albumen. In the yolk about $0.021 \mathrm{~g} / 100 \mathrm{~g}(0.111 \%)$ could not be accounted for, may be due to other FAs that were in traces; in the albumen about $0.01 \mathrm{e}-4 \mathrm{~g} / 100 \mathrm{~g}(0.120$ $\%)$ could not be accounted for.

Table 7 contains the various phospholipids levels. Lecithin was the most concentrated among the phospholipids although in trace level (like other phospholipids) in the albumen. For example lecithin was $115 \mathrm{mg} / 100 \mathrm{~g}$ or $46.0 \%$ in the yolk; it was $23.3 \mathrm{e}-$ $3(63.1 \%)$ in the albumen.

Among the sterols in Table 8, stigmasterol (135 $\mathrm{mg} / 100 \mathrm{~g}$ or $35.0 \%$ ) was the most concentrated in the yolk while other sterols ranged from 82.2-86.3 $\mathrm{mg} / 100 \mathrm{~g}$ or $21.3-22.4 \%$. Sterol was not detected in the albumen.

\section{DISCUSSION}

Chicken eggs are the most commonly-eaten eggs. They are also an inexpensive single-food source of protein. The yolk and albumen values from literature showed close correlation with the present report: $33.04 \pm 0.40 \%$ (chicken yolk), $32.68 \pm 0.39 \%$ (guineafowl yolk); $57.1 \pm 0.45 \%$ (chicken albumen), $50.3 \pm 0.44 \%$ (guinea-fowl albumen) (Adenowo et al., 1999). Another source (Eggs and fetal development, 2009) reported that yolk makes up about $33 \%$ of the liquid weight of the egg.

Results in Table 2 showed that the yolk contained virtually all of the fat.

Table 3 indicated that $\mathrm{C} 14: 0, \mathrm{C} 16: 0, \mathrm{C} 18: 0$ and C24:0 were the SFA in both samples. The total SFA from C14:0, C16:0 and C18:0 in the yolk was $32.1 \%$ and $27.6 \%$ in the albumen. These three SFA in particular enhance LDL cholesterol concentration. People on a low-cholesterol diet may need to reduce egg consumption, particularly egg yolk. Literature report showed that SFA profile in eggs was C12:0 (0 $\%)$, C14:0 (0\%), C16:0 (27\%) and C18:0 (10\%) (Ma et al.,1995). The present values had good correlation with the literature values cited. There is debate over whether egg yolk presents a health risk. Some research suggested that dietary cholesterol increases the ratio of total cholesterol to HDL cholesterol and, therefore, adversely affects body's cholesterol profile (Weggemans et al., 2001) whereas other studies showed that moderate consumption of eggs up to two per day, does not appear to increase heart disease risk in healthy individuals (Hu et al., 1999). Harold and McGee argued that the cholesterol in the yolk is not what causes a problem, because fat (particularly saturated) is much more likely to raise cholesterol levels than the actual consumption of cholesterol (Egg food, 2009). Epidemiological studies of heart disease have implicated the four major SFAs to varying degrees. The $\mathrm{WHO}$ has determined that there is "convincing" evidence that C14:0 and C16:0 intake increases the probability, "possible" risk from C12:0 and no increased risk at all from C18:0 consumption (WHO Disease Specific Recommendations, 2010). These four SFAs were relatively low in the present results.

C18:1n-6, cis was the most concentrated MUFA in yolk whereas C18:1n-9, cis was the most concentrated MUFA in albumen. For the trans-MUFA, C18:1n-11, trans was the most concentrated MUFA (trans) in the two samples, while MUFA (cis) total was $19.6 \%$ (yolk) and $16.9 \%$ (albumen); MUFA (trans) total was $24.0 \%$ (yolk) and $26.0 \%$ (albumen). From literature, egg had $22.98 \mu \mathrm{g} / \mathrm{ml}$ of $\mathrm{C} 18: 1 \mathrm{n}-9$, trans (LECO Corporation, 2003). The natural trans fatty acids in butter are said not to be harmful and may even have health-promoting properties, such as preventing certain forms of cancer (Wardlaw, 2003).

In Table 4 C18:2n-6, cis was the most concentrated n-6 PUFA in both samples. The n-6 PUFA (totals) values were close in both samples with $\mathrm{CV} \%$ of 10.2 . The only C18:2n-6, trans had a value of $1.57 \%$ in yolk and $2.30 \%$ in the albumen. C18: $2 n-6$, trans is known as conjugated linoleic acid (CLA) which occurs naturally. All the n-3 FAs were in traces. This meant that food sources with better levels of $n-3$ PUFA should be consumed with the chicken egg to provide the essential FAs. The relative amounts of PUFA and SFA in oils is important in nutrition and health. The ratio of PUFA/SFA (P/S ratio) is therefore important in determining the detrimental effects of dietary fats. The higher the $\mathrm{P} / \mathrm{S}$ ratio the more nutritionally useful is oil. The $\mathrm{P} / \mathrm{S}$ ratio was 0.62 (yolk) and 0.79 (albumen) which were good to discourage atherosclerosis tendency.

The results in Table 5 showed a positively high and significant $r_{x y}$ at $r=0.05$. The $r_{x y}{ }^{2}$ was also high showing that $99.5 \%$ of variance in the albumen $(Y)$ was associated with the variance in the yolk $(X)$. The $R_{x y}$ showed that for every unit increase in the yolk FAs there was a corresponding increase of 0.492 in the $\mathrm{FA}$ of the albumen. The $\mathrm{C}_{\mathrm{A}}$ was low at 0.069 (or 6.9 
\%) with a corresponding high value of index of forecasting efficiency (IFE) with a value of 0.931 (or $93.1 \%)$. The IFE is actually a value of reduction in the error of prediction of relationship between the yolk and the albumen FAs. This meant that the error in the prediction of relationship was just $6.90 \%$. The implication of this was that the yolk FAs could carry out adequately the functions of the albumen FAs of chicken eggs.

The phospholipids (Table 7) can only be said to be present in the yolk when compared with the values in the albumen. Lecithin (phosphatidylcholine) was the most abundant phospholipid forming about $46 \%$ in the yolk. It is the key building block of membrane bilayers. Choline in one yolk contains approximately half of the recommended daily intake. Choline is an important nutrient for development of the brain, and is said to be important for pregnant and nursing women to ensure healthy fetal brain development (Eggs and fetal development, 2009). Cephalin was the second largest phospholipid in the samples. It is found in all living cells, although in human physiology it is found particularly in nervous tissue such as the white matter of brain, nerves, neutral tissue and in spinal cord (Phosphatidylethanolamine, 2009). The phosphatidylserine (PS) of $17.4 \mathrm{mg} / 100 \mathrm{~g}$ was close to $16.0 \mathrm{mg} / 100 \mathrm{~g}$ reported for European pilchard (sardine) (Alter, 2006). The US Food and Drug Administration (USFDA) had said that consumption of PS might reduce the risk of dementia in the elderly and may also reduce the risk of cognitive dysfunction in the elderly (Phosphatidylethanolamine, 2009). Phosphatidylinositol (PI) was the least concentrated. The inositol can be phosphotylated to form phosphatidylinositol phosphate (PIP), PI bisphosphate $\left(\mathrm{PIP}_{2}\right)$ and $\mathrm{PI}$ trisphosphate $\left(\mathrm{PIP}_{3}\right)$. PIP, $\mathrm{PIP}_{2}$ and $\mathrm{PIP}_{3}$ are collectively called phosphoinositides. Phosphoinositides play important roles in lipid signaling, cell signaling and membrane trafficking (Phosphatidylethanolamine, 2009). Partial hydrolysis of lecithin with removal of only one fatty acid yields a lysophosphatidylcholine (White et al., 1994).

Table 8 shows stig - masterol as the highest sterol in chicken egg yolk with a value of $135 \mathrm{mg} / 100 \mathrm{~g}$ or $35.0 \%$. Stig- masterol is used as a precursor in the manufacture of synthetic progresterone, a valuable human hormone that plays an important physiological role in the regulatory and tissue rebuilding mechanisms related to estrogen effects, as well as acting as an intermediate in the biosynthesis of endrogens, estrogens and corticoids. Studies with laboratory animals fed stig-masterol found that both cholesterol and sitosterol absorption decreased $23 \%$ and $30 \%$ respectively over a 6 week period (Stigmasterol, 2009). Both cholestanol and sitosterol had close values of $82.2 \mathrm{mg} / 100 \mathrm{~g}(21.3 \%)$ and 82.7 $\mathrm{mg} / 100 \mathrm{~g}(21.4 \%)$ respectively. Cholesterol enters the intestinal tract by excretion across the intestinal mucosa as well as via the bile. In the lumen of the gut a portion is reduced microbially to coprostanol and cholestanol and thereby is excluded from absorption. These two sterols, together with cholesterols, constitute the bulk of the fecal sterols. Certain of these transformations, e.g., from cholestenone to cholestanol, also occur in the liver (White et al., 1994). The levels of cholestanol could have come from cholesterol breakdown and liver transformation of cholestenone. A large yolk is said to contain more than two-thirds of the recommended daily intake of cholesterol (although one study indicated that the human body may not absorb much cholesterol from eggs) (University Science article on eggs and cholesterol, 2009).

The present report of cholesterol level of $86.3 \mathrm{mg} / 100$ $\mathrm{g}$ was much lower than the value of $424 \mathrm{mg}$ reported for an American chicken egg (Egg food, 2009). The good aspects of cholesterol included being present in mammalian cell membranes where it is required to establish proper membrane permeability and fluidity, a precursor molecule for the biosynthesis of bile acids, steroid hormones and several fat soluble vitamins. Cholesterol does one negative influence in the body, however. On its way into cells from the blood stream, some cholesterol forms deposits in the artery walls. These deposits lead to atherosclerosis, a disease that causes heart attacks and strokes. The present report of $86.3 \mathrm{mg} / 100 \mathrm{~g}$ cholesterol would be about one- third $(1 / 3)$ of the recommended daily intake of $300 \mathrm{mg} / 100 \mathrm{~g}$ cholesterol and about onequarter (1/4) of the USDA value of $424 \mathrm{mg}$ from chicken egg (Egg food, 2009). 
Table 1: Mean egg weight (g) and percent nutrient content ( $\pm S D)$ for the chicken

\begin{tabular}{llll}
\hline Total egg weight & Yolk & Albumen & Shell \\
\hline $32.0 \pm 1.39$ & $10.5 \pm 0.33(32.8 \%)$ & $17.2 \pm 1.53(53.8 \%)$ & $3.44 \pm 0.30(10.8 \%)$ \\
\hline
\end{tabular}

Table 2.:Crude and total fatty acid levels of yolk and albumen $(\mathrm{g} / \mathbf{1 0 0} \mathrm{g})$ of the chicken

\begin{tabular}{llllll}
\hline Parameter & Yolk & Albumen & Mean & SD & CV \% \\
\hline Crude fat & 22.9 & 0.001 & 11.5 & 16.2 & 141 \\
Total fatty acid* & 19.0 & 0.00083 & 9.51 & 13.4 & 141 \\
\hline
\end{tabular}

* Crude fat $\times 0.83 ; \mathrm{SD}=$ standard deviation; $\mathrm{CV} \%=$ coefficient of variation.

Table 3: Saturated and monounsaturated fatty acid composition of the yolk and albumen of chicken (\% total fatty acids)

\begin{tabular}{llllll}
\hline Fatty acid & Yolk & Albumen & Mean & SD & CV \% \\
\hline C12:0 & Tr & Tr & - & - & - \\
C14:0 & 0.885 & 0.483 & 0.684 & 0.28 & 41.6 \\
C16:0 & 21.1 & 18.2 & 19.7 & 2.05 & 10.4 \\
C18:0 & 10.1 & 8.87 & 9.49 & 0.87 & 9.17 \\
C20:0 & $\operatorname{Tr}$ & $\operatorname{Tr}$ & - & - & - \\
C22:0 & $\operatorname{Tr}$ & 0.137 & - & - & - \\
C24:0 & 2.92 & 4.15 & 3.54 & 0.87 & 24.6 \\
SFA & 35.0 & 31.8 & 33.4 & 2.26 & 6.77 \\
C14:1 n-5, cis & 0.246 & 0.191 & 0.219 & 0.04 & 17.8 \\
C16:1 n-7, cis & 3.56 & 2.84 & 3.20 & 0.51 & 15.9 \\
C18:1 n-6, cis & 8.65 & 6.53 & 7.59 & 1.50 & 19.8 \\
C18:1 n-9, cis & 7.11 & 7.33 & 7.22 & 0.16 & 2.15 \\
C20:1 n-9, cis & - & $\operatorname{Tr}$ & - & - & - \\
C22:1 n-9, cis & - & - & - & - & - \\
C24:1 n-9, cis & - & - & - & - & - \\
MUFA (cis) & 19.6 & 16.9 & 18.3 & 1.91 & 10.5 \\
C18:1 n-6 trans & 4.65 & 5.75 & 5.20 & 0.78 & 15.0 \\
C18:1 n-9, trans & 8.40 & 8.22 & 8.31 & 0.13 & 1.53 \\
C18:1 n-11, trans & 10.9 & 12.0 & 11.5 & 0.78 & 6.79 \\
MUFA (trans) & 24.0 & 26.0 & 25.0 & 1.41 & 5.66 \\
MUFA (totals) & 43.5 & 42.9 & 43.2 & 0.42 & 0.98 \\
\hline
\end{tabular}

$\operatorname{Tr}$ = trace; - = not detected; SFA = saturated fatty acids; MUFA = monounsaturated fatty acid. 
Agric. Biol. J. N. Am., 2012, 3(9): 374-384

Table 4: PUFA n-6 and n-3 fatty acid composition of the yolk and albumen of chicken (\% fatty acids)

\begin{tabular}{|c|c|c|c|c|c|}
\hline Fatty acid & Yolk & Albumen & Mean & SD & CV \% \\
\hline C18:2 n-6, cis & 15.8 & 18.6 & 17.2 & 1.98 & 11.5 \\
\hline C18:3 n-6, cis & $\operatorname{Tr}$ & $\operatorname{Tr}$ & - & - & - \\
\hline C20:2 n-6, cis & $\operatorname{Tr}$ & $\operatorname{Tr}$ & - & - & - \\
\hline C20:3 n-6, cis & 1.81 & 1.31 & 1.56 & 0.35 & 22.7 \\
\hline C20:4 n-6, cis & 2.61 & 2.98 & 2.80 & 0.26 & 9.36 \\
\hline C22:2 n-6, cis & - & - & - & - & - \\
\hline n-6PUFA (cis) & 20.2 & 22.9 & 21.6 & 1.91 & 8.86 \\
\hline C18:2 n-6, trans & 1.57 & 2.30 & 1.94 & 0.52 & 26.7 \\
\hline n-6 PUFA (totals) & 21.8 & 25.2 & 23.5 & 2.40 & 10.2 \\
\hline C18:3 n-3 & $\operatorname{Tr}$ & $\operatorname{Tr}$ & - & - & - \\
\hline C18:5 n-3 & $\operatorname{Tr}$ & $\operatorname{Tr}$ & - & - & - \\
\hline$C 22: 6 n-3$ & $\mathrm{Tr}$ & $\mathrm{Tr}$ & - & - & - \\
\hline$n-6+n-3$ (PUFA) & 21.8 & 25.2 & 23.5 & 2.40 & 10.2 \\
\hline Totals (SFA+MUFA & & & & & \\
\hline + PUFA & 100 & 99.9 & 100 & 0.07 & 0.07 \\
\hline Totals (MUFA+PUFA) & 65.3 & 68.1 & 66.7 & 1.98 & 2.97 \\
\hline PUFA/SFA & 0.62 & 0.79 & 0.705 & 0.12 & 17.1 \\
\hline $2 n-6 / 3 n-3$ & - & - & - & - & - \\
\hline Ratio & \multicolumn{2}{|c|}{$1: 0.996$} & - & - & - \\
\hline
\end{tabular}

PUFA = unsaturated fatty acid (essential fatty acid). 
Table 5: Statistical analysis of the results from Tables 3 and 4

\begin{tabular}{|c|c|c|c|c|c|c|c|c|}
\hline Parameter & Yolk(X) & Albumen(Y) & Y) $r_{x y}$ & $r_{x y}^{2}$ & $\mathrm{C}_{\mathrm{A}}$ & $\mathrm{R}_{\mathrm{xy}}$ & IFE & Remar \\
\hline SFA & 35.0 & 31.8 & & & & & & \\
\hline MUFA (totals) & 43.5 & 42.9 & & & & & & \\
\hline n-6+n-3PUFA & 21.8 & 25.2 & & & & & & \\
\hline Totals & 100 & 99.9 & & & & & & \\
\hline MUFA+PUFA & 65.3 & 68.1 & 0.9976 & 0.9952 & 0.492 & 0.06 & 0.931 & * \\
\hline MUFA/SFA & 0.62 & 0.79 & & & & & & \\
\hline Mean & 44.4 & 44.8 & & & & & & \\
\hline $\pm S D$ & 34.9 & 34.8 & & & & & & \\
\hline CV \% & 78.6 & 77.7 & & & & & & \\
\hline
\end{tabular}

$r_{x y}=$ correlation coefficient; $r_{x y}{ }^{2}=$ coefficient of determination; $R_{x y}=$ regression coefficient; $C_{A}=$ coefficient of alienation; IFE = index of forecasting efficiency; ${ }^{*}=$ result significantly different at $n-2$ and $r=0.05$.

Table 6: Fatty acid levels in the egg per $100 \mathrm{~g}$ yolk and albumen samples as food

\begin{tabular}{lll}
\hline Fatty acid & Yolk & Albumen \\
\hline C14:0 & 0.163 & $4.00 \mathrm{e}-6$ \\
C16:0 & 4.02 & $1.51 \mathrm{e}-4$ \\
C18:0 & 1.91 & $7.36 \mathrm{e}-4$ \\
C22:0 & - & $1.41 \mathrm{e}-6$ \\
C24:0 & 0.555 & $3.44 \mathrm{e}-5$ \\
C14:1 n-5, cis & 0.047 & $1.58 \mathrm{e}-6$ \\
C16:1 n-7, cis & 0.677 & $2.36 \mathrm{e}-5$ \\
C18:1 n-6, cis & 1.64 & $5.42 \mathrm{e}-5$ \\
C18:1 n-9, cis & 1.35 & $6.08 \mathrm{e}-5$ \\
C18:1 n-6 trans & 0.819 & $4.77 \mathrm{e}-5$ \\
C18:1 n-9, trans & 1.60 & $6.82 \mathrm{e}-5$ \\
C18:1 n-11, trans & 2.06 & $1.00 \mathrm{e}-4$ \\
C18:2 n-6, cis & 3.00 & $1.54 \mathrm{e}-4$ \\
C20:3 n-6, cis & 0.344 & $1.09 \mathrm{e}-5$ \\
C20:4 n-6, cis & 0.496 & $2.48 \mathrm{e}-5$ \\
C18:2 n-6, trans & 0.299 & $1.91 \mathrm{e}-5$ \\
Totals & 19.0 & $8.29 \mathrm{e}-4$ \\
Difference & $0.02(0.111 \%)$ & $0.01(0.120 \%)$ \\
\hline
\end{tabular}


Agric. Biol. J. N. Am., 2012, 3(9): 374-384

Table 7: Phospholipid levels ( $\mathrm{mg} / 100 \mathrm{~g}$ ) of yolk and albumen of chicken

\begin{tabular}{|c|c|c|}
\hline Phospholipid & Yolk & Albumen \\
\hline Cephalin (PE) & 78.3 (31.3\%) & 6.27 e-3 (17.0\%) \\
\hline Lecithin & $115(46.0 \%)$ & 23.3 e-3 $(63.1 \%)$ \\
\hline Ptd-L-Ser (PS) & $17.4(6.96 \%)$ & 1.73 e-3 (4.69 \%) \\
\hline Lysophosphatidylcholine & $24.3(9.72 \%)$ & 4.49 e-3 (12.2\%) \\
\hline Ptdlns (PI) & $14.9(5.90 \%)$ & 1.09 e-3 (2.95\%) \\
\hline Totals & 250 & 36.9 e-3 \\
\hline \multicolumn{3}{|c|}{$\begin{array}{l}\mathrm{PE}=\text { phosphotidylethanolamine; Lecithin = phosphatidylcholine; } \mathrm{PS}= \\
\text { phosphatidylinosotol. }\end{array}$} \\
\hline \multicolumn{3}{|c|}{ Table 8: Sterol levels $(\mathrm{mg} / 100 \mathrm{~g})$ of yolk and albumen of chicker } \\
\hline Sterol & Yolk & Albumen \\
\hline Cholesterol & $86.3(22.4 \%)$ & - \\
\hline Cholestanol & $82.2(21.3 \%)$ & - \\
\hline Stig-masterol & $135(35.0 \%)$ & - \\
\hline Sitosterol & $82.7(21.4 \%)$ & - \\
\hline Totals & 386 & - \\
\hline
\end{tabular}

\section{CONCLUSIONS}

Free- range eggs are considered by some advocates to be acceptable substitute to factory-farmed eggs. Free- range laying hens are given outdoor access instead of being contained in crowded cages. In this report the yolk was found to be concentrated in crude fat; total fatty acid; moderate levels of SFA, MUFA, n6 PUFA; higher than average PUFA/SFA values; high in lecithin and cephalin; high in stig-masterol and below average in cholesterol. The chicken egg (freerange) may probably be better in nutritional qualities than many eggs. It should however be noted that the unpredictable diet of free-range hens will produce unpredictable eggs (Egg Food, 2009).

\section{REFERENCES}

Adenowo, J.A., Awe, F.A., Adebambo, O.A., Ikeobi, C.O.N., (1999). Species variations in chemical composition of local poultry eggs. In: Book of Proceedings $26^{\text {th }}$ Annual NSAP Conference 21-25 March, 1999 llorin, Nigeria. pp.278-280.

Alter, T., (2006). More than you wanted to know about fat and oil. Sundane Natural Food Online retrieved 200608-31.
AOAC International, (2005). Official methods of analysis of AOAC International, $18^{\text {th }}$ edition. Association of Official Analytical Chemists Maryland, USA.

Egg food - Wikipedia, the free encyclopedia. http://en.wikipedia.org/wiki/Egg-(food). Accessed on 17 October 2009.

Eggs and fetal development (http://www.pdrheaalth.com/druginfo/nmdrugprofiles/nutsupdrugs/cho 0283.shml). Accessed 11-3-2009.

Greenfield, H. and Southgate, D.A.T., (2003). Food composition data, production, management and use. FAO Rome, pp. 223-224.

Hu, F.B., Stampfer, M.J., Rimm, E.B., et al., (1999). A prospective study of egg consumption and risk of cardiovascular disease in men and women. JAMA, 281 (15): 1387-1394.

LECO CORPORATION, (2008). Determination of fatty acid methyl esters by GC $x$ GC-TOFMS. LECO Corporation, Michigan, pp. 1-4.

Ma ,J., Folsom, Ar., Shahar, E. and Eckfeldt, Jh., (1995). Plasma fatty acid composition as an indicator of habitual dietary intake in middle- aged adults. The Atherosclerosis Risk in Communities (ARIC) Study 
Investigators. The American Journal of Clinical Nutrition, 62 (3): 564-571.

Montagne, P., (2001). Larousse Gastronomique. Clarkson Potter, New York, pp. 447-448.

Oloyo, R.A., (2001). Fundamentals of research methodology for social and applied sciences. ROA Educational Press, llaro, Nigeria, pp. 71-73.

Paul, A.A. and Southgate, D.A.T., (1978). McCance and Widdowson's The Composition of foods, $4^{\text {th }}$ edition, HMSO, London.

Phillips, K.M., Wolf, W.R., Patterson, K.Y., Sharpless, K.E., Ammanna, K.R. and Holden, J.M., 2007. Summary of reference materials for the determination of nutrient composition of foods. Accred Qual Assur, 12: 126-133.

Phosphatidylethanolamine. http://en.wikipedia.org/wiki/phosphatidylethanolamine.

Accessed on 17 October 2009.

Raheja, R.K., Kaur, C., Singh, A. and Bhatia, I.S., (1973). New colorimetric method for the quantitative estimation of phospholipids without acid digestion. Journal of Lipid Research, 14: 695-697.

Roux, M. and Brigdale, M., (2006). Eggs. Wiley New York, pp.1-8.
Stadelman, W., (1995). Egg Science and Technology. Haworth Press, New York, pp. 1-2.

Stigmasterol. http://en.wikipedia.org/wiki/stigmasterol. Accessed on 28 August 2009.

University Science article on eggs and Cholesterol. http://unisci.com/steries/20014/1029013.htm. Accessed on 3 November 2009.

Wardlaw, G.M., (2003). Contemporary nutrition: issues and insights, $5^{\text {th }}$ edition. McGraw Hill, Boston, pp.164-165.

Weggemans, R.M., Zock, P.L. and Katan, M.B., (2001). Dietary cholesterol from eggs increases the ratio of total cholesterol to high -density lipoprotein cholesterol in humans: a meta-analysis. Am. J. Clin. Nutr., 73 (5): 885-891.

White, A., Handler, P. and Smith, E.L., (1994). Understanding normal and clinical nutrition. West Publishing Company, New York pp. 542-603.

World Health Organization Disease Specific Recommendations.

http://www.who.int/nutrition/topics/5-

population nutrient/en/index12.html. Accessed on 23 February 2010. 